\title{
Conserved Peptide with Therapeutic Potential to Overcome Nasopharyngeal Carcinoma
}

\author{
Muhaimin $\mathrm{R}^{\mathrm{a}}$, Widyarti $\mathrm{S}^{\mathrm{b}}$, Widodo $\mathrm{N}^{\mathrm{c}}$ \\ aDepartment of Immunology, Faculty of Sciences, Brawijaya University, Malang, Indonesia \\ ${ }^{b}$ Department of Molecular Biology, Faculty of Sciences, Brawijaya University, Malang, Indonesia \\ 'Department of Oncology and Biocomputation, Faculty of Sciences, Brawijaya University, Malang, Indonesia
}

\begin{abstract}
Nasopharyngeal carcinoma (NPC) is a squamous-cell carcinoma that arises in the upper lining epithelium of the nasopharynx. In this study, conserved peptide (Ulin-1) of Epstein-Barr virus constructed by Biomodelling and Biocomputation was tested for its ability to stimulate B cells to produce specific antibodies. Spleen cells were isolated and cultured with anti-CD3 and lipopolysaccharide (LPS), and treated or not treated with Ulin-1. Cell culture was harvested six days after incubation and analyzed by flow cytometry. Here, we demonstrated the ability of Ulin-1 to stimulate B cells to produce specific antibodies. The results of this study illustrate the importance of Ulin-1 engineered by Biomodelling and Biocomputation as both active and passive immunization agents against nasopharyngeal cancer.
\end{abstract}

KEYWORDS: Nasopharyngeal carcinoma, Ulin-1, gp 350/220, in vitro.

\section{INTRODUCTION}

Nasopharyngeal carcinoma (NPC) is a malignant tumor derived from the nasopharyngeal epithelium. It occurs in the nasopharynx area located behind the nose and above the back of the throat. It is commonly found in Southeast Asia, Southern China and Hong Kong. ${ }^{1-4}$ Medium prevalence of nasopharyngeal carcinoma occurs to people in Africa, Mediterranean, Malays in Singapore, Indonesia, and Malaysia.. ${ }^{5-7}$ According to Devi et al. the risk of Bidayuh people in Sarawak State, Malaysia to suffer from NPC is higher than the highest recorded by any other population-based registries around the same period. ${ }^{8}$ In Indonesia, nasopharyngeal carcinoma is most often found among malignant tumors in the field of ENT (Ear Nose and Throat). Its incidence is often found in patients over the age of 40 years, and its prevalence is quite high, namely 4.7 cases per year in 100.000 populations or in estimated 7000-8000 cases per year in Indonesia. ${ }^{9}$ Nasopharyngeal carcinoma (NPC) is an Epstein-Barr virus (EBV) associated malignancy. ${ }^{8,10-14}$ EBV is a DNA virus with icosahedral capsid structure. ${ }^{15-18}$ Receptors considered to play a role in EBV entry into epithelial cells of nasopharyngeal is CD21/CR2. ${ }^{18-19}$ Nasopharyngeal

Corresponding author:

Muhaimin Rifa'i, Ph.D.

Department of Immunology,

Faculty of Sciences,

Brawijaya University,

Malang 65145, Indonesia

Phone: 62-341-575841;

Fax: 62-341-575841;

e-mail: rifa123@ub.ac.id carcinoma prevention is still an issue, because the suitable and effective vaccine to inhibit EBV entry has not been found, as well as the hidden location of the nasopharynx. Nasopharyngeal carcinoma is generally asymptomatic until it reaches an advanced stage; thereby, it causes difficulty in a diagnosis and therapy. Therefore, it is necessary to prevent the disease through effective and non-toxic vaccination. ${ }^{20-25}$ However, manufacturing EBV vaccine requires a good strategy by considering that EBV has many variants/ strains. ${ }^{26-28}$ Making a vaccine that works on all strains of EBV with conventional methods would require a long time and is expensive, so that a new strategy to make EBV vaccine to cover all the strains is very important thing to do. ${ }^{24,29}$ Constructing EBV vaccine could be done carefully, quickly and accurately by Biocomputation and Biomodelling approach, and then tested by in vitro and in vivo systems, in order to obtain a high quality of vaccine. ${ }^{24,26,29-31}$ Until now, radiotherapy remains an important option for therapy because a safer strategy has not been found. ${ }^{33-39}$

Based on the description above, a research to design a vaccine that works to inhibit the growth of nasopharyngeal carcinoma based on conserved regions of EBV that binds the host cell receptor is urgent and very important. Therefore, the aim of this study was to demonstrate Ulin-1 to stimulate EBV-specific B cells, and the outcome of this effort was to find a potential strategy for future therapeutic interventions in NPC. 


\section{MATERIALS AND METHODS}

\section{Mice}

Seven week-old female BALB/c mice were purchased from Gajah Mada University. They were maintained in pathogen-free condition in the Department of Molecular Biology at Brawijaya University, Indonesia. This study was approved by Ethics Committee of Brawijaya University, Indonesia.

\section{Conserved Peptide (Ulin-1)}

Conserved peptide was constructed by Biomodelling and Biocomputation. The conserved peptide used in this experiment consisted of 19-mer and was labeled Ulin-1.

\section{Cell Culture and Antibody Induction in vitro}

B lymphocytes were obtained from the spleen of seven week-old mice. Spleen cells were washed twice with PBS and resuspended with Iscove's medium of sodium bicarbonate containing $10 \%$ fetal calf serum (FCS), gentamycin, or RPMI-1640 medium added to gentamicin $0.01 \mathrm{mg} / \mathrm{ml}$, two $\mathrm{mM} \mathrm{L-Gluta-mine,} \mathrm{trypticase} \mathrm{soy}$ broth $0.03 \mathrm{mg} / 100 \mathrm{ml}$, and $10 \%$ heat-inactivated fetal calf serum (Flow Laboratories, McLean, VA). Spleen cells $\left(2 \times 10^{6} /\right.$ well) were cultured in $1.5 \mathrm{ml}$ of RPMI1640 medium containing 10\% FCS, glutamin (30 $\mathrm{\mu g} /$ $\mathrm{ml})$, penicillin $(100 \mathrm{U} / \mathrm{ml})$, streptomycin $(100 \mu \mathrm{g} / \mathrm{ml})$, 2-ME $\left(5 \times 10^{-5} \mathrm{M}\right)$ in 24-well flat-bottom culture plates (Costar, Cambridge, MA) with anti-CD3 (2\% culture supernatant), LPS (10 ng/ml, Sigma), IL-2 (10 $\mu \mathrm{g} / \mathrm{ml})$, and added to or without Ulin-1 (booked commercially) $1,000 \mathrm{ng} / \mathrm{ml}$. Then the cells were incubated at $37^{\circ} \mathrm{C}$ in $5 \% \mathrm{CO}_{2}$ for 3 to 6 days.

\section{Detection of Antibody Production by Flow Cytometry}

Cell suspensions harvested from cell culture were incubated for 30 minutes at $4^{\circ} \mathrm{C}$ with FACS buffer (PBS, $1 \%$ bovine growth serum and $0.01 \% \mathrm{NaN}_{3}$ ). Samples were centrifuged and pellets were re-suspended in FACS buffer containing fluorochrome-conjugated antibody for 30 minutes at $4^{\circ} \mathrm{C}$. The antibody used in this study were anti-B220 FITC (BD Biosciences, San Jose, CA, USA); PECy5-conjugated anti-IgG (BD Biosciences), PE-conjugated anti-lgE (BD Biosciences), PECy7-conjugated anti-lgD (Biolegand). Antibodies were purchased from eBioscience (San Diego, CA, USA) unless indicated. After washing, cells were re-suspended in FACS buffer and collected on a BD FACSCalibur flow cytometer. Data analysis was performed by using CellQuest. Intracellular antibody staining was performed in spleenic cell cultures according to the protocol provided by the manufacturer. At day 3 and 6, cells were collected, washed and subsequently permeabilized and stained for intracellular antibody, and the surface was stained for membrane antigens.

\section{Statistical Analysis}

Data were analyzed using ONE-way ANOVA at $p<0.05$ and Tukey HSD test using SPSS 16.0 for Windows.

\section{RESULTS}

Ulin-1 derived from proteins gp350/220 of EBV could stimulate $B$ cells to produce a specific antibody. In addition to Ulin-1 $1,000 \mathrm{ng} / \mathrm{ml}$ in cell culture, they profoundly increased antibody expression $(p<0.05)$ compared to the control groups. In this experiment, it was known that in the first three days of post culture, antibodies had not yet been synthesized. In general, all immunoglobulin can be detected only after six days of post-culture. The addition of anti-CD3 in spleen cell cultures can support $T$ cell survival, while the addition of LPS can support the APC survival (antigen presenting cells). Another interesting point of this study was that the Ulin-1 designed by Biomodelling and Biocomputation approaches was not an allergen. This result can therefore be an effective strategy for cancer immunotherapy.

\section{DISCUSSIONS}

$B$ cells are one of the important components in the immune system which controls foreign antigens. These cells in turn synthesize antibodies when exposed to the appropriate antigen. Many studies describe the importance and function of B cells. ${ }^{33-35}$ To perform the function as a component of immune system, B cells cooperate with other cells such as $T$ cells, dendritic cells, and macrophages. Ulin-1 derived from gp350/220 proteins could stimulate $B$ cells to produce antibodies (Fig. 1). To see the possibility of B cells which had synthesized antibodies in the early exposure of the given peptide, we analyzed the expression of antibodies at day 3 of post culture. The results of analysis at day 3 of post culture gave evidence that the antibodies had not yet been produced at the cellular level (Fig. 2 ). These results illustrated that $B$ cells responding to antigen took time, and was different from the innate immune components which could respond to antigen spontaneously. There are at least two factors leading to the emergence of antibodies (IgG) which is relatively late. First, the dose of antigen is too small. Second, clones that match the given antigen are very little. The second possibility is more reasonable than the first one, since most peptides in the range of $1-10000 \mathrm{ng} / \mathrm{ml}$ is enough to stimulate $B$ cells to produce antibodies. 


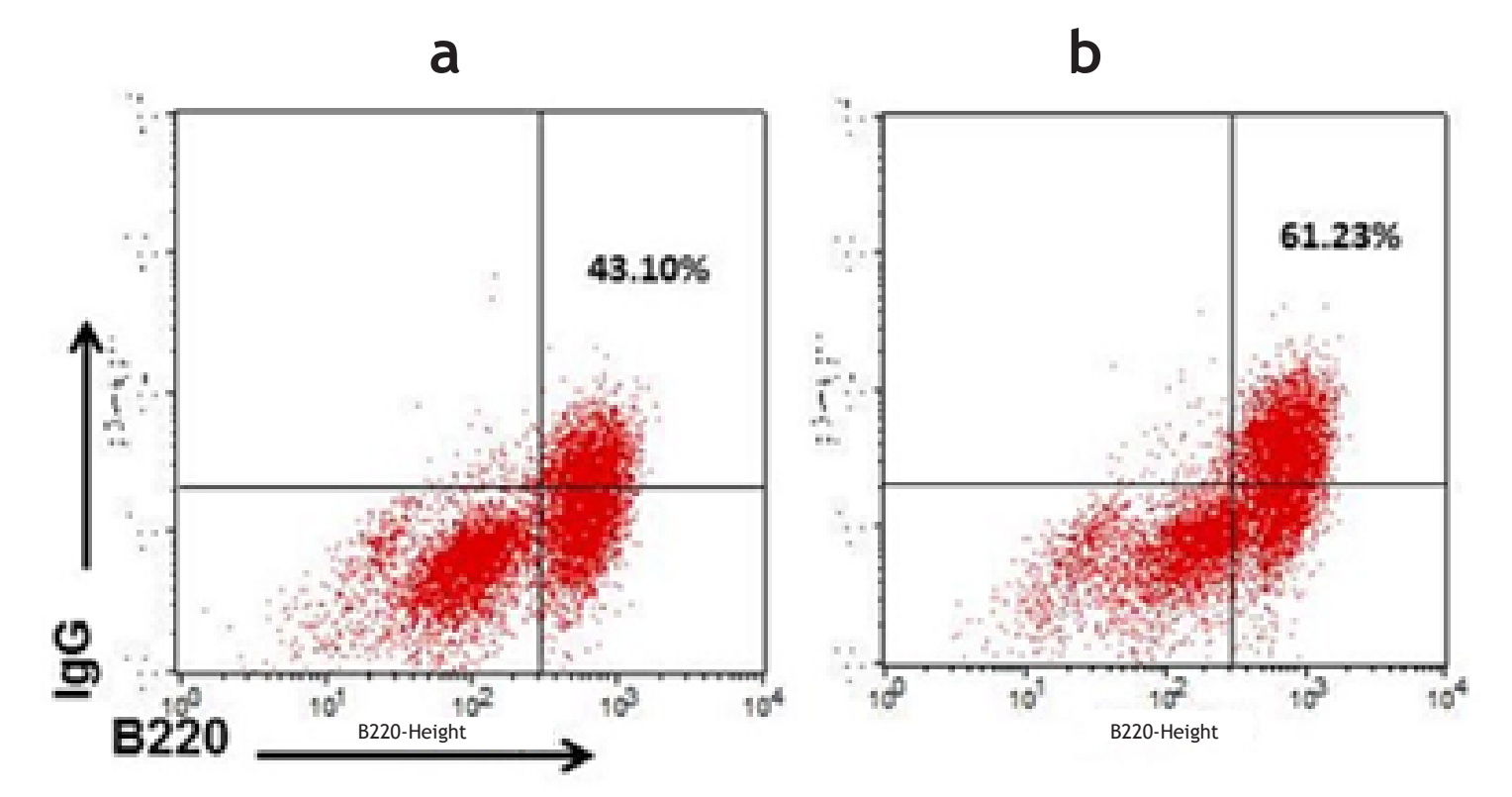

Figure 1. Ulin-1 derived from gp350/220 protein could stimulate B cells to produce specific antibodies. Spleen cells were cultured in RPMI medium for six days. a, Anti-CD3 and LPS were added to the culture. b, Anti-CD3, LPS, and Ulin-1 were added to the culture. On day 6, cell culture was harvested and analyzed by flow cytometry. Percentages of B220 cells positively stained by intracellular lgG were presented in the panels. Data were mean \pm SD values of five mice in each group.

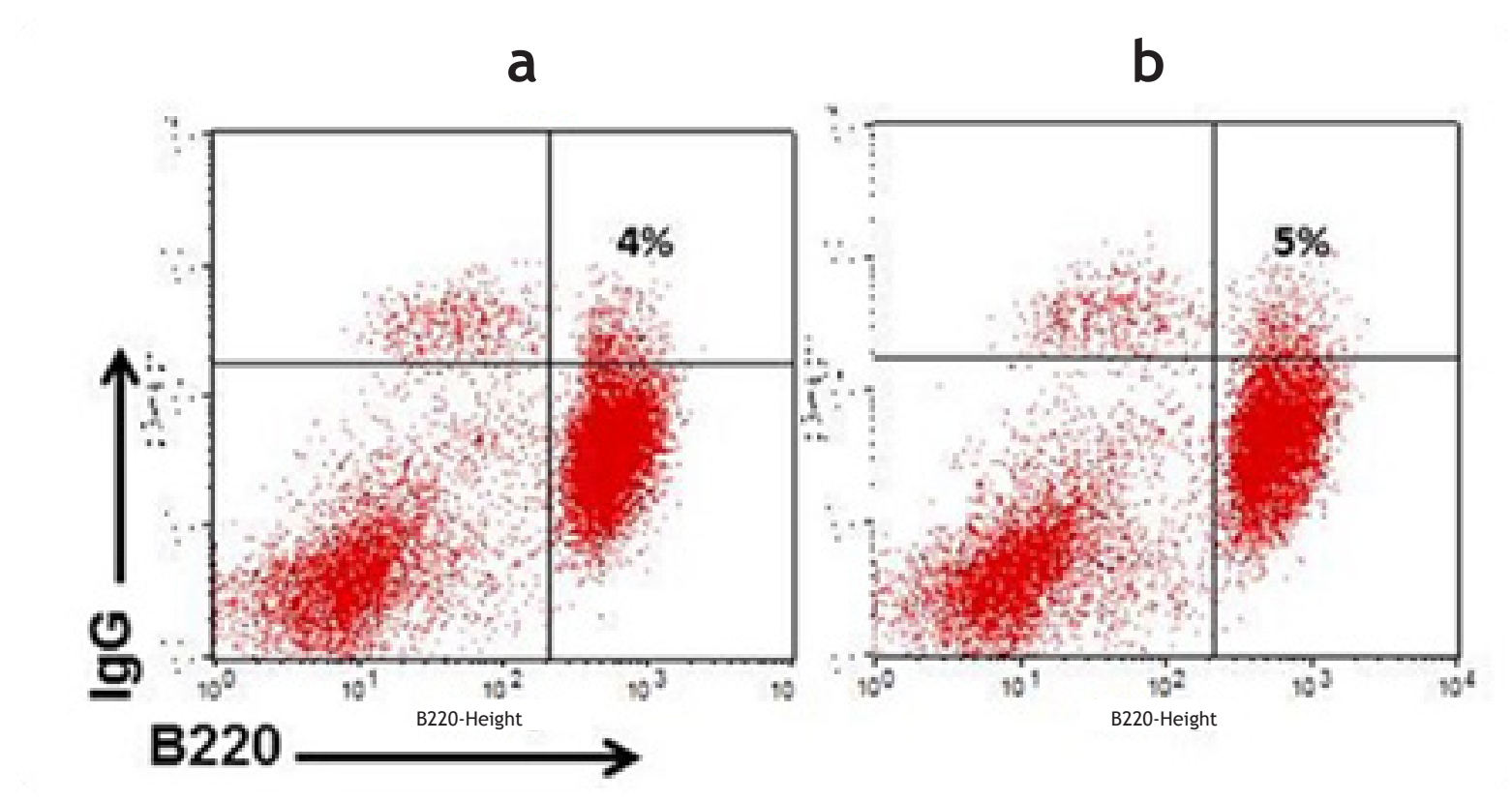

Figure 2. Stimulation of B cells with Ulin-1 for three days showed no increase in antibody synthesis. Spleen cells were cultured in RPMI medium for three days. a, Anti-CD3 and LPS were added to the culture. b, Anti-CD3, LPS, and Ulin-1 were added to the culture. On day 3, cell culture was harvested and analyzed by flow cytometry. Percentages of B220 cells positively stained by intracellular lgG were presented in the panels. Data were mean \pm SD values of five mice in each group. 
In this study, all of spleen mononuclear cells were cultured together without division by sorting. It was intended to allow cooperation between cells involved in the immune responses. In this culture, anti-CD3 was added to sustain the population of CD4 $\mathrm{T}$ cells in particular, to increase the survival. CD4 $\mathrm{T}$ cell populations were required to sustain $B$ cell proliferation. LPS and peptide will be presented by MHC class II on macrophages, which in turn stimulate CD4 T cells to produce IL-2. IL-2 is required by $B$ cells to survive and also to maintain proliferation. In addition, the added peptide may directly stimulate competent $B$ cells, so that the cells will start to produce antibodies. 36-37 Macrophages, monocytes, and some lymphocytes have $\mathrm{Fc}$ receptors that will bind with the Fc region of IgG. IgG bindings in some cells mentioned above are very beneficial to the immune responses because they can promote the internalization of antigen entry. Complexes antigen antibody which have been internalized by the APC will be digested and processed in the cytoplasm and presented by MHC class II. ${ }^{38-39}$ IgG is often referred as an opsonin regarding its functions to enhance phagocytosis. An association of IgG with Fc receptors on the cell will result in the activation and function of the cells in immune responses. In this experiment, we had evidence that the stimuli with the Ulin-1 did not cause IgE production. IgE was one of the antibodies closely associated with allergic reactions (Fig. 3). IgE bound very strongly with Fc receptors of basophils and mast cells, although no antigen interacted with that immunoglobulin. The consequence of that very strong bond was a very low concentration of IgE in serum, because most IgE was tied to the tissue. IgE contributes to the incidence of allergic reactions. The association of IgE with antigen causes the secretion of several molecular mediators affecting allergic symptoms. IgE plays an important role to eradicate the parasite, such as the worm larvae (helminth). In cases of illness caused by helminth, the concentration of IgE in serum increases so that it can be used for diagnostic test of this parasite type. Eosinophils have Fc receptors for IgE binding. ${ }^{40}$ The association of eosinophils to IgE on the surface of helminth causes the death of this parasite. In this study, IgE was checked for the possibility of allergic reactions to peptide stimulation constructed by Biomodelling and Biocomputation.

To observe the ability of specific clone activation against the peptide, we analyzed the expression of IgD. IgD is an antibody located on the B cell-surface functioning as a receptor of $B$ cells. The importance of IgD has been described in many different views. ${ }^{34-35}$ While TCR (T cells receptor) functions as an activation tool for $T$ cells, IgD is an activation tool for $B$ cells. IgD increase on the $B$ cell surface after peptide addition gives an evidence of the suitability of this peptide with B cell receptors, so that B cells turn into plasma and synthesize specific immunoglobulins against that peptide. The analysis of $B$ cells in vitro after six days of post culture in the presence of peptide (Fig. 4) showed a significant increase in IgD production $(p<0.05)$.

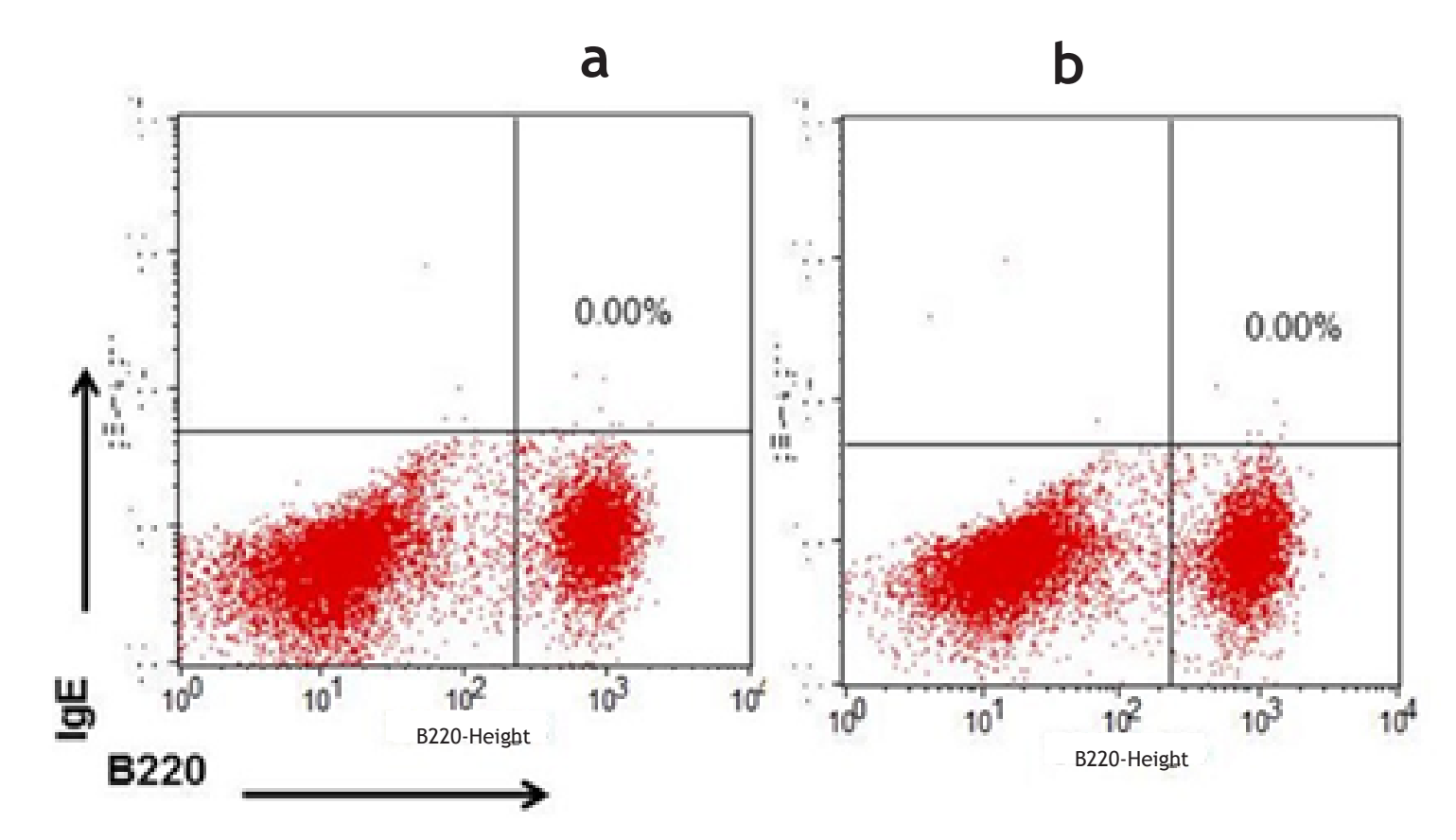

Figure 3. Peptide engineered by Biomodelling and Biocomputation (Ulin-1) did not have the nature of allergen. Spleen cells were cultured in RPMI-1640 medium for six days. a, Anti-CD3 and LPS were added to the culture. b, Anti-CD3, LPS, and Ulin-1 were added to the culture. On day 6, cell culture was harvested and analyzed by flow cytometry. Percentages of B220 cells positively stained by intracellular IgE were presented in the panels. Data were mean \pm SD values of five mice in each group. 
a

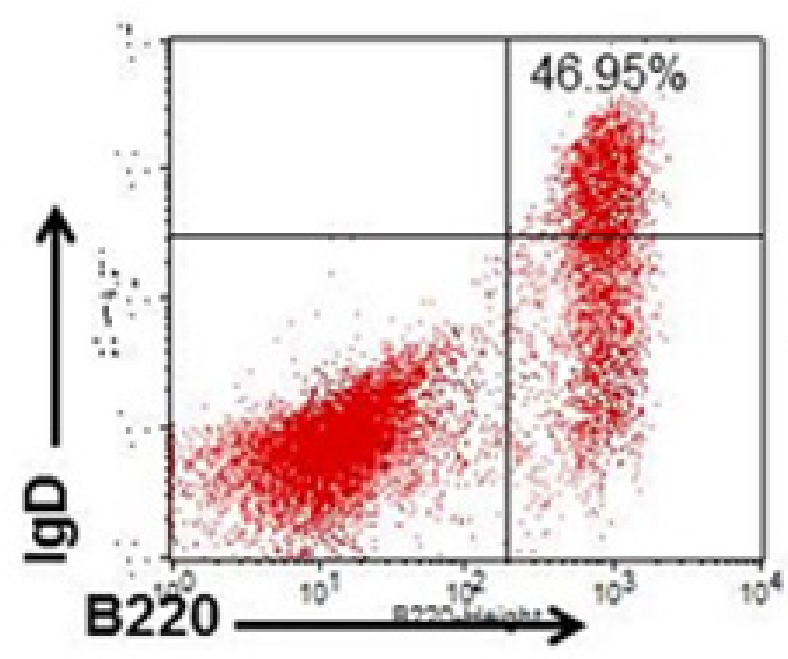

b

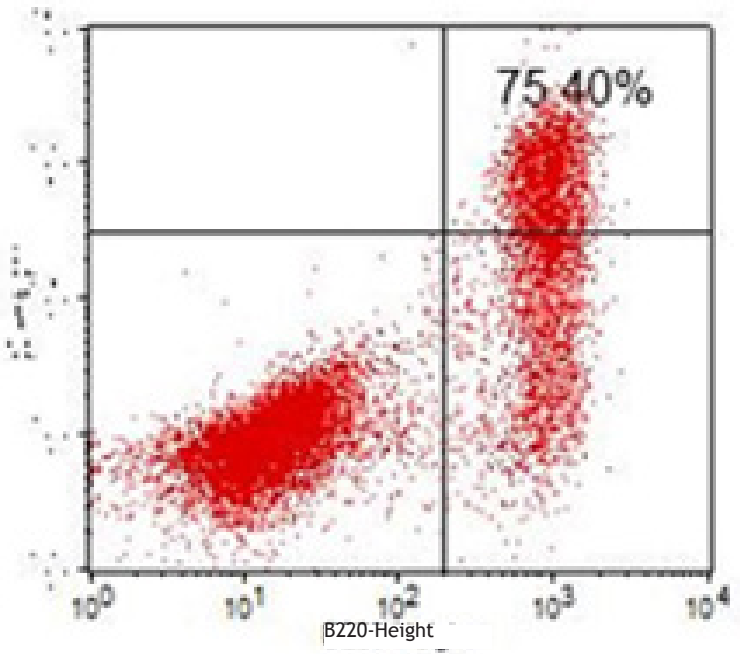

Figure 4. Stimulation of B cells by using Ulin-1 for six days showed the increase of IgD synthesis. Spleen cells were cultured in RPMI medium for six days. a, Anti-CD3 and LPS were added to the culture. b, Anti-CD3, LPS, and Ulin-1 were added to the culture. On day 6 , cell culture was harvested and analyzed by flow cytometry. Percentages of B220 cells positively stained by intracellular IgD were presented in the panels. Data were mean $\pm \mathrm{SD}$ values of five mice in each group

\section{CONCLUSION}

Epitope of gp 350/220 EBV, particularly Ulin-1 constructed by Biomodelling and Biocomputation can stimulate $B$ cells to produce antibodies in vitro. The Ulin-1 is not an allergen and has a nature to change naïve $B$ cells to plasma cells in vitro. It has a capacity to be a potent candidate for active and passive vaccines, which are important to overcome nasopharyngeal cancer.

\section{ACKNOWLEDGEMENTS}

The authors would like to thank Brawijaya University Malang, Indonesia for providing study necessities, and Indonesian Ministry of Higher Education for supporting the financial under the Competitive Research Grant Scheme $(0636 / 023-04.2 .16 / 15 / 2012)$

\section{REFERENCES}

1. Brennan B. Nasopharyngeal carcinoma. Orphanet $\mathrm{J}$ Rare Dis 2006; 1:23:1-5.

2. Lalonde A, Avila-Carino J, Caruso M. Rescue of the immunotherapeutic potential of a novel $T$ cell epitope in the Epstein-Barr virus latent membrane protein 2. Virology 2007; 361:253-62.

3. Chan JKC, Pilch BZ, Kuo TT, et al. Tumours of the nasopharynx In: WHO classification of tumours : pathology and genetics of head and neck tumours. IARC Press 2005; 81-5.

4. Darnell SJ, Laura L, Mitchell JC. KFC Server: interactive forecasting of protein interaction hot spots. Nucleic Acids Res 2008; 36:265-69.

5. Fachiroh J, Schouten T, Hariwiyanto B, et al.
Molecular diversity of Epstein Barr virus IgG and IgA antibody responses in nasopharyngeal carcinoma: A comparison of Indonesian, Chinese, and European subjects. J Infect Dis 2004; 190:53-62.

6. Ou SH, Zell JA, Ziogas A, Anton-Culver H. Epidemiology of nasopharyngeal carcinoma in the United States: improved survival of Chinese patients within the keratinizing squamous cell carcinoma histology. Ann Oncol 2007; 18:29-35.

7. Niedobitek G. Epstein-Barr virus infection in the pathogenesis of nasopharyngeal carcinoma. Mol Pathol 2000; 53:248-54.

8. Devi BCR, Pisani P, Tang TS, Parkin DM. High incidence of nasopharyngeal cancer in the native people of Sarawak, Borneo Island. Cancer Epidemiol Biomarkers Prev 2004; 13:482-6.

9. Lee AWM, Foo W, Mang O, et al. Changing epidemiology of nasopharyngeal carcinoma in Hong Kong over a 20 year period (1980-1999): an encouraging reduction in both incidence and mortality. Int J Cancer 2003; 103:680-5.

10. Swanson-Mungerson $M$, Ikeda $M$, Lev $L$, Longnecker R, Portis T. Identification of latent membrane protein 2A (LMP2A) specific targets for treatment and eradication of Epstein-Barr virus (EBV)-associated diseases. J Antimicrob Chemother 2003; 52:152-4.

11. Chou J, Yu CL, Kim J, et al. Nasopharyngeal carcinoma-review of the molecular mechanisms of tumorigenesis. Head Neck 2008; 30:946-63.

12. Mafee MF, Rasouli F, Spigos DG, et al. Magnetic resonance imaging in the diagnosis of nonsquamous tumors of the head and neck. 
Otolaryngol Clin North Am 1986; 19:523-36.

13. Chijioke O, Azzi T, Nadal D, Münz C. Innate immune responses against Epstein Barr virus infection. J Leukoc Biol 2013; 94:1185-90.

14. Thomson MP, Kurzrock R. Epstein-Barr virus and cancer. Clin Cancer Res 2004; 10:803-21.

15. Korcum AF, Ozyar E, Ayhan A. Epstein-Barr virus genes and nasopharyngeal cancer. Turkish Journal of Cancer 2006; 36:97-103.

16. Rodriguez GC, Wofford M, Castleberry RP, et al. Preradiation chemotherapy with methotrexate, cisplatin, 5 fluorouracil, and leucovorin for pediatric nasopharyngeal carcinoma. Cancer 2005; 103:850-7.

17. Lollini PL, Cavallo F, Nanni P, Forni G. Vaccines for tumour prevention. Nat Rev Cancer 2006; 6:204-16.

18. Raghavan D, Brecher ML, Johnson DH, Meropol NJ, Moots PL, Rose PG, eds. John Wiley \& Sons, 2006:113-5.

19. Pazdur MP, Jones JL. Vaccines: an innovative approach to treating cancer. J Infus Nurs 2007; 30:173-8.

20. Arkin M, Wells J. Small-molecule inhibitors of protein-protein interactions: progressing towards the dream. Nat Rev Drug Discov 2004; 3:301-7.

21. Lo YM, Leung SF, Chan LY, et al. Kinetics of plasma Epstein-Barr virus DNA during radiation therapy for nasopharyngeal carcinoma. Cancer Res 2000; 60:2351-5.

22. Arvin A, Campadelli FG, Mocarski E. Human Herpesviruses: Biology, therapy, and immunoprophylaxis. Cambridge: Cambridge University Press, 2007.

23. Larsen JEP, Lund O, Nielsen M. Improved method for predicting linear B-cell epitopes. Immunome Res 2006; 2:2-5.

24. Utomo DH, Widodo N, Rifa'i M. Identifications small molecules inhibitor of p53-mortalin complex for cancer drug using virtual screening. Bioinformation 2012; 8:426-9.

25. Sprenger J, Fink JL, Teasdale RD. Evolution dan comparison of mammalian subcellular localisation prediction methods. BMC Bioinformatic 2006; 7:2-7.

26. Jenkin RD, Anderson JR, Jereb B, et al. Nasopharyngeal carcinoma - a retrospective review of patients less than thirty years of age: a report of Children's Cancer Study Group. Cancer 1981; 47:360-6.

27. American Joint Committee on Cancer. Pharynx. In: AJCC Cancer Staging Manual, 7th ed. New York: Springer-Verlag, 2010:41-49.

28. Lin JC, Wang WY, Chen KY, et al. Quantification of plasma Epstein-Barr virus DNA in patients with advanced nasopharyngeal carcinoma. N Engl J Med 2004; 350:2461-70.

29. Mauri C, Bosma A. Immune regulatory function of B cells. Annu Rev Immunol 2012; 30:221-41.

30. Komano H, Ikegami Y, Yokoyama M, et al. Severe impairment of B cell function in $\mathrm{lpr} / \mathrm{lpr}$ mice expressing transgenic Fas selectively on $B$ cells. Int Immunol 1999; 11:1035-42.
31. Mertens R, Granzen B, Lassay L, et al. Treatment of nasopharyngeal carcinoma in children and adolescents: definitive results of a multicenter study (NPC-91-GPOH). Cancer 2005; 104:1083-9.

32. Rifa'i M. Andrographolide ameliorate rheumatoid arthritis by promoting the development of regulatory $\mathrm{T}$ cells. Journal of Tropical Life Science 2011; 1:5-8.

33. Vazquez A, Auffredou MT, Galanaud P, Leca G. Modulation of IL-2- and IL-4-dependent human $B$ cell proliferation by cyclic AMP. J Immunol 1991; 146:4222-7.

34. Seifert M, Kuppers R. Molecular footprints of a germinal center derivation of human $\lg M+(\lg D+)$ CD27+ $B$ cells and the dynamics of memory $B$ cell generation. J Exp Med 2009; 206:2659-669.

35. Menno CVZ. Human CD27+lgM+lgD+ B cells: T-cell or TLR-dependent? Blood 2012; 120:4905-6.

36. Lenardo MJ. Interleukin-2 programs mouse alpha beta T lymphocytes for apoptosis. Nature 1991; 353:858-61.

37. Dennig D, Mecheri S, Hoffman MK. Interleukin-2 may enhance or inhibit antibody production by $B$ cells depending on intracellular cAMP concentrations. Immunology 1992; 77:251-5.

38. Clement LT, Giorgi JV, Plaeger-Marshall S, et al. Abnormal differentiation of immunoregulatory $\mathrm{T}$ lymphocyte subpopulations in the major histocompatibility complex (MHC) class II antigen deficiency syndrome. J Clin Immunol 1988; 8:503-12.

39. Plaeger-Marshall S, Haas A, Clement LT, et al. Interferon-induced expression of class II major histocompatibility antigens in the major histocompatibility complex (MHC) class II deficiency syndrome. J Clin Immunol 1988; 8: 285-295.

40. Gould HJ, Sutton BJ. IgE in allergy and asthma today. Nat Rev Immunol 2008; 8:205-17. 